\title{
Bien trascendental: salvación y comunidad fuerte en F. Suárez
}

\author{
Giannina Burlando \\ FACULTAD DE FILOSOFÍA \\ PONTIFICIA UNIVERSIDAD CATÓLICA DE CHILE \\ gburland@uc.cl
}

Resumen: Intento destacar algunos vínculos entre la nociones de bien trascendental, salvación y comunidad en el pensamiento de Suárez; me parece que este aspira a establecer bases morales para resignificar la relación del individuo y el Estado liberal moderno de su época. La hipótesis central del trabajo es que la reflexión suarista acerca de la comunidad arroja como resultado no la esencial 'comunión', ni una organización de organismo mecánico, ni un ejercicio de inmanencia de sus miembros, ni que sus miembros sean primordialmente sujetos, ni que ellos puedan coestar juntos, sino y ante todo, que la comunidad es relación: una en la que sus miembros ejercen 'intrínseca ordenación a otro', es decir, una relación a y con la alteridad. Otra hipótesis interna del presente trabajo es que la particular onto- teo -política de la comunidad en Suárez alcanzaría un sentido holístico fuerte, ya que no solo está modelada autárquicamente, sino sobre la base moral del trascendental bonum, siendo este último el que funge como fundamento del ser-común ${ }^{1}$.

Palabras Clave: Suárez, teoría política, bien trascendental, salvación, comunidad fuerte.

Abstract: I intend to highlight some links between the notions of trascendental Good, salvation and community within Suarez's thought. I think that it aims to establish moral basis for resignifiyng the relationship of the

1 Este trabajo es producto del proyecto Fondecyt No 1110434. Paralelamente se enmarca dentro del Proyecto I+D+I Pensamiento y tradición jesuita y su influencia en la Modernidad desde las perspectivas de la Historia, la Traductología y la Filosofía Jurídica, Moral y Politica. Financiado por el Ministerio de Economía y Competitividad, y por el Fondo Europeo de Desarrollo Regional (Mineco/Feder, referencia FFI2015-64451-R), cuyo investigador principal es el Prof. Dr. Juan Antonio Senent de Frutos. 
individual and the modern liberal State of his time. The main hypothesis of this work is that the outcome of suarezian insight about the community is not that of an esential 'communion', nor the organization of a mechanical organism, neither an immanent exercise of their members or that their members are primarily subjects, neither that subjects may be together, but rather and above all, that the community is a relation: one wherein their members excercise an 'intrinsic ordination to the other one', namely, a relation to and with the otherness. Another internal hypothesis of the present work is that the particular onto-theo-politics of the community in Suarez would reach a holistic strong sense, since not only it is shaped autarchicaly, but also on the moral base of the trascendental bonum, being the latter what act as a fundation of the common- being.

Key Words: Suarez, political theory, trascendental Good, salvation, strong community.

\section{INTRODUCCIÓN}

"[...] ut Aristoteles testatur, principium rerum omnium moralium est finis." (Suárez, De fine hominis)

Entre los intérpretes contemporáneos de Suárez hay acuerdo básico acerca de que en sus Disputaciones Metafísicas (1597), recoge todo el acervo metafísico de la Edad Media - con ella, los problemas y principios fundamentales de la metafísica- para orientarlos hacia los problemas y principios trascendentales de la Edad Moderna. El centro de estas discusiones ha sido fundamentalmente el valor de esta orientación. Por una parte, críticos como Aubenque ${ }^{2}$, Courtine $^{3}, V_{\text {olpi }}^{4}$, Darge $^{5}$, Söchting ${ }^{6}$, et al. han mostrado una decisiva valoración del giro de la metafísica suareziana

2 P. Aubenque, Le problème de l'être chez Aristote, Paris, 1966.

3 J. F. Courtine, Suarez et le système de la métaphysique (PUF, Paris 1990).

4 F. Volpi, "Suarez et le problème de la metaphysique", en Review de Metaphysique et de Morale, 3 (1993) 395-411.

5 R. DARge, "Ens intime transcendit omnia: Suarez Modell der transzendentalen Analyse und die mittelalterlichen Transzendentalienlehren”, Freiburger Zeitschrift für Philosophie und Theologie 47 (2000) 150-172.

6 J. Söchting, Perfecto en Humanidad: El misterio de la encarnación como problema ontológico en la Disputationes Metaphysicae de Francisco Suárez, S. J. (Tesis 
hacia el mentalismo, entendido este en el sentido de una preocupación problemática hacia las condiciones de posibilidad del pensamiento del ser en el sujeto; otros, como Gracia ${ }^{7}$ y Hellín ${ }^{8}$, han sostenido que, si bien es cierto que el pensamiento de Suárez admite una lectura que orienta hacia el "mentalismo", sigue moviéndose dentro de los problemas y las categorías del realismo y, por tanto, dentro de la metafísica escolástica. En consonancia con esas interpretaciones antinómicas, otros estudiosos como José Pereira $(2007)^{9}$, Lorella Cedroni (1996) ${ }^{10}$; Pedro Calafate $(1999)^{11}$, Antonio Mendo Castro Henriques (2004) ${ }^{12}$, John Doyle $(2011)^{13}$, Jean Paul Coujou $(2010 ; 2012)^{14}$ o Sidney Penner $(2013)^{15}$, Leopoldo Prieto $(2013)^{16}$, Gonçalo Pistacchini Moita $(2014)^{17}$ y otros,

de Magíster de Teología Dogmática, Facultad de Teología, Pontificia Universidad Católica de Chile, 2007).

7 J. Gracia, "The Ontological Status of the Trascendental Attributes of Being in Scholasticism and Modernity: Suárez and Kant”, en Jan A. Aertsen, Andreas Speer (eds.), Was ist philosophie im Mittelalter, (Walter de Gruyter Miscellanea Medievalia 26, Berlin 1998 213-225); J. GRACIA, "Suárez and the Doctrine of Trascendentals", en Topoi 11 (1992) 121-133.

8 J. Hellín, "El ente real y los posibles en Suárez”, en Espiritu 10 (1961) 146-163.

9 J. Pereira, Between Scholasticism and Modernity (Marquette U. P. Milwaukee WI, 2007).

10 L. Cedroni, La comunità perfetta. Il pensiero politico di Francisco Suárez. (Edizioni Studium, Roma 1996).

11 P. Calafate, "A Idea de Soberania em Francisco Suárez", en A. Cardoso, et al. (Eds.), Francisco Suárez (1548-1616), (Tradição e Modernidade Ed. Colibri, Lisboa 1999).

12 M. Castro, J. A. Maltez, A. Morão, G. Pistacchini Moita (eds.), F. Suárez, De Legibus ac Deo Legislatore. Libro I Da lei en geral. (Ed. Tribuna da História, Lisboa 2004).

13 J. Doyle, Collected Studies on Francisco Suárez, S.J. (1548-1617), (Leuven University Press, Belgium 2010 208).

14 J. P. Coujou, "La constitution suarézienne de l'unitée trascendentale et ses implications anthropologico-politiques", Revue philosophique de Louvain, 1084 (2010) 585-615; J. P. Coujou, Pensée de L'Être et Théorie Politique Le Moment Suarézien, (Éditions Peeters, Louvain/Paris 2012).

J. F. Courtine, Suarez et le système de la métaphysique (PUF, Paris 1990).

15 S. Penner, "The Pope and Prince of All the Metaphysicians: Some Recent Works on Suarez", en British Journal for the History of Philosophy, 212 (2013) 393 - 403.

16 L. Prieto, Suárez y el destino de la metafísica: de Avicena a Heidegger (BAC, Madrid 2013).

17 G. Pistacchini Moita, A Modernidade Filosófica de Francisco Suárez (Imprensa Nacional Casa da Moeda, Lisboa 2014). 
independientemente han avanzado hacia la valoración de las derivaciones de tal orientación, aceptando implícita o explícitamente que tratándose de ontología trascendental, ellos prefieren explorar directamente en el campo de la posible conexión con la teoría política de Suárez. En efecto, Coujou en particular, ha defendido que existe una relación recíproca implícita entre el trascendental Unum, la unidad individual y la unidad política del ser-en común en la filosofía de Suárez (cf. nota 49). Dado esta hermenéutica, la amplitud y dificultad del tema, mi propósito es bastante modesto. Seguiré la formulación metodológica de la pregunta de Coujou, i.e., "si acaso puede concebirse las determinaciones trascendentales sin el ser o, viceversa, el ser sin estas"; pero, esta vez, para pasar a inferir una extensión moral-política de la misma cuestión, a saber: ¿puede una manifestación específica del ser, como aquella del ser-en-común en el orden político -encarnado en la comunidad humana- disociarse del carácter del bien trascendental? Mi delimitación programática será exponer sobre la doctrina teológica suareziana de la bondad trascendental, y sus implicaciones antropológico-políticas ${ }^{18}$. Sin embargo, en mi parecer, no solo el lenguaje de la antropología y de la teoría política "renuevan el pensamiento sobre el ser-individual, a su vez, completan la comprensión del modo de ser del ser", como ha notado Coujou, sino que uno de los aportes más claros para tal renovación surge a partir de su teología, cuyo claro objetivo no es solo el conocimiento especulativo acerca de Dios, sino uno práctico y moral, por lo mismo, se interesa en el ámbito de la acción humana y su relación al bien ${ }^{19}$; ciertamente también involucra el propio método de la orientación trascendental desde ya instalado en la ontología de Suárez; por tanto, necesitaremos partir echando luz sobre el uso que Suárez hace del concepto 'trascendental' o 'trascendentalidad'. Así, procedemos en la sección I. a caracterizar el uso de la noción trascendental en la ontología de Suárez; en la sección II. a analizar la comprensión teológica del trascendental bonum en Suárez; y en la sección III. a comentar el alcance del bien moral: la teoría sua-

18 Reviso el uso suareziano de 'trascendental' con el propósito de buscar una relación recíproca implícita entre metafísica, antropología y política, y esto quiere decir entre los postulados teórico descriptivos de las Disputationes metaphysicae (1597) y las prescripciones pragmáticas del De Legibus ac Deo legistatore (1612) y algunas teológicas del tratado de la Defensio fidei Catholicae adversus Anglicanae sectae errores (1613), y De fine hominis, en Edición latina de Vivés, 1628.

19 Suárez, De fine hominis, Proemium. 
reziana de la libertad, la ley natural, el poder político, su teología de la salvación y su noción de la comunidad perfecta, de todo lo cual se deriva el sentido en que estos factores conforman la relación entre el individuo y el Estado liberal moderno.

\section{USO DE LA NOCIÓN 'TRASCENDENTAL' EN LA ONTOLOGÍA DE SUÁREZ}

Una premisa fundamental que sostiene la conexión entre la metafísica y los problemas e interrogantes concernientes a contenidos de orden práctico (antropológico, ético y político) está en la misma constitución suarista de una ontología trascendental, cuyo objeto de estudio es el ser entendido como ser real; el cual halla su principio y condición de inteligibilidad en sus "razones universales trascendentales", o sus passionibus in communi: lo uno, verdadero y bueno. Determinaciones trascendentales que pertenecen y se vinculan al ser al punto de convertirse coextensivamente con el mismo ser. Para explicar, sin embargo, qué significa en general que la ontología trascendental halla su principio y condición de inteligibilidad en sus razones universales trascendentales, recurrimos al uso del término 'trascendental' ${ }^{20}$. En verdad, hay que tener cuidado en notar que para Suárez 'trascendental', por un lado, sigue denotando el sentido clásico según el cual la unidad, la verdad y la bondad son propiedades del ser que están más allá del universal ${ }^{21}$. De tal suerte que

20 J. Gracia reconoce que las Disputationes II - XI de Suárez abordan explícitamente los trascendentales y las maneras en que podemos distinguir entre ellos. "For Suarez 'thing' and 'something' are not true properties of being, but rather different names for the same thing. Like D. Scotus, Suarez admits just three properties of being: one, truth and good, which are in fact all properties or attributes of being in the sense of 'trascendental' properties. Suarez used the term 'transcendens' and/or 'trascendentalis', meaning literally 'climbing-beyond' or 'climbing-across', to refer to the fact that these properties, just like being, with which they were coextensive, were not restricted to any one category or group of categories but extended to all of them. It can be noticed a slight different emphasis introduced by Suarez in the very titles of disputations VI, VIII and X where he deals, respectively, with one, truth and good as passiones trascendentales: De Unitate Formali et Universali; De Veritate seu vero, Quod est Passio Entis; De Bono seu Bonitate Trascendentali (SuÁrez, DM III $23)$. Ontological bonum, as we shall see, is convertible, coextensive with being, and like being: 'metaphysically abstracted'”. (Cf.; J. Gracia - D. Davis, The Metaphysics of Good and Evil according to Suarez (Philosophia Verlag, München 1989), 65-6).

21 Cf. Suárez, DM VI, VIII, 12. Cito desde F. SuÁrez, Disputationes Metaphysicae, S. Rábade, S. Caballero y A. Puigcerver, Trads. (Gredos, Madrid 1960-1967). En adelante $D M$. 
trascendental se interpreta como: lo que se comunica o extiende más allá de otras cosas.

Sin embargo, por otro lado, Suárez va más allá: vincula el fundamento de la propiedad trascendental, con la capacidad del intelecto de realizar una abstracción metafísica (distinta de la física, que abstrae la materia; y de la matemática, que abstrae la cantidad). De este modo: "la verdad trascendental significa la entidad de la cosa connotando el conocimiento o concepto intelectual a que dicha entidad se adecua, o en el que esa cosa está o puede estar representada tal como es" (Suárez, DMVIII, VII, 25); mientras que "la bondad trascendental, tomada abstractamente, puede ser considerada una propiedad del ser, aunque en particular ha de ser atribuida a cada ser según un modo propio y un tipo (rationem) de bondad y conveniencia"22.

Debemos notar que lo propio suareziano en tales definiciones es que esas razones, aspectos o determinaciones, son un tipo de abstracción metafísica; justamente “... se dice, ... que abstrae de la materia sensible e inteligible, no solo según la razón, sino según el ser, porque las razones del ente que considera se hallan en la realidad sin materia y, por tanto, en su concepto propio y objetivo de por sí no incluye la materia (...). Luego, la metafísica extiende su consideración hasta todos los entes o razones de ser que se contienen en la referida abstracción, y no pasa más allá porque lo que queda es propio del campo de la física o de la matemática"23. De este modo, la abstracción metafísica obtiene como resultado las propiedades trascendentales que son, en síntesis, relaciones que se establecen respecto del ser real de los objetos ${ }^{24}$.

22 Cf. SuÁrez, DM X I 10. "Si el 'Bien' es tomado abstractamente cuando se dice de cada ser, no significa que cada tipo (ratio) de bien, es decir, el noble, el útil y el placentero, se halle en cada ser, sino [solo] la naturaleza del bien [rationem] sin cualificación. Esto será verdadero dado que al menos algún tipo (ratio) de bien se encontrara en cada ser." (SuÁrez, DMX I 10). Por otra parte, 'bondad' significa la entidad de la cosa connotando "el aspecto (rationem) de agradable/o de conveniente. Este no es propiamente una relación, sino que solamente connota en otro una naturaleza teniendo una inclinación, capacidad, o conjunción natural con tal perfección. Por tanto, la bondad expressa la misma perfección de una cosa, connotando la mencionada conveniencia o la denotación que surge de la coexixtencia de muchos" (SuÁreZ, DMX I 12). (Agrego cursivas)

23 SuÁrez DM I, II, 13.

24 "En la perspectiva de Suárez los seres reales son absolutamente autónomos del intelecto, que son los seres singulares e individuales, cuyas formas, no obstante, son 
Es en este momento donde se percibe el "giro" hacia el mentalismo de Suárez y la vinculación con la metafísica trascendental estándar de $\mathrm{Kant}^{25}$, según establece Söchting ${ }^{26}$. Las relaciones trascendentales, a diferencia de las relaciones predicamentales, no requieren de un fundamento real absoluto, entendido este en el sentido de la existencia actual y formal (extramental); tampoco, de un término real de la relación ni, finalmente, de un fundamento real de la relación. De este modo Suárez explica el caso de la ciencia de un objeto posible: "También muchas veces este respecto trascendental, aunque se ordena a un término real, no exige, empero, la real existencia del mismo, como la ciencia de un eclipse futuro dice una referencia real trascendental al eclipse, aunque no exista; y lo mismo sucede en cualquier ciencia de un objeto posible, y en la potencia respecto del acto no existente" 27 . De modo que las realidades antropológico-políticas, que enseguida consideramos, pueden ser apreciadas desde alguna propiedad trascendental que se ha establecido respecto del ser real de los objetos. Así pues, para analizar el vínculo de la ontología trascendental con las cuestiones concernientes a contenidos de orden práctico, antropológico, ético y político será necesario abordar en particular la extensión de la noción del trascendental bonum.

universales (nunca existiendo en acto), sino en potencia de ser conocidos por el intelecto. Puesto que la metafísica es la ciencia del ente, en cuanto ente real (Cf. DM I, I, 26); cuya unidad se basa en su concepto objetivo (Cf. SuÁrez, DM II, II, 8). La posibilidad de esta unidad proviene de la unidad del acto a través del cual pensamos lo ente del ente real -acto que Suárez llama concepto formal- (Cf. SuÁREZ, DM II, I, 9). Una vez determinada la extensión trascendental de este concepto objetivo, será posible, entonces, determinar sus divisiones: desde las mayores (ser infinito -que es Dios- y ser finito -que es la creatura-) hasta los últimos componentes, propiedades y relaciones de cada uno de los miembros de ellas. De este modo, se establece el carácter sistemático de la metafísica que será un requisito trascendental para la constitución de la ciencia. La metafísica es desde esta óptica una ciencia posible y consistente. Suárez basa la posibilidad de la metafísica en la unidad de su concepto objetivo." (Cf. J. Söchting, Perfecto en Humanidad: El misterio de la encarnación como problema ontológico en la Disputationes Metaphysicae de Francisco Suárez, S. J. (Tesis de Magíster de Teología Dogmática, Facultad de Teología, Pontificia Universidad Católica de Chile, 2007).

25 En cuanto a lo que Kant significó con la idea de un sistema completo de filosofía trascendental, esto es, un sistema de todos los principios de la razón pura; un sistema de conceptos que se ocupa, no tanto de los objetos, sino de nuestro modo de conocerlos en tanto que tal modo ha de ser posible a priori.

26 J. Söchting, Perfecto en Humanidad..., 220.

27 SuÁrez, DM XLVII, IV, 2. 


\section{AnÁlisis del trascendental Bonum en SuÁreZ}

Jorge Gracia, en su examen de la Disputación $\mathrm{X}^{28}$, ha notado que Suárez no estaría de acuerdo con la convicción de G. E. Moore, para quien la búsqueda de una definición del bien sería un procedimiento ilícito; tampoco está de acuerdo con las diversas definiciones del bien que han sido propuestas desde los griegos antiguos hasta Santo Tomás, ya sea en términos de placer, virtud, honor, fama, felicidad, objeto de deseo, el deseo sin más o la deseabilidad. Suárez rechaza claramente la difundida identificación de lo bueno con lo deseable ${ }^{29}$. De modo que no coincide con la definición esencial dada por Sto. Tomás, esta es: "La esencia de la bondad consiste en esto, que algo sea deseable"30, o que "el bien expresa la noción de deseable". Suárez defiende alternativamente que el bien, o la bondad en general, pueden definirse en términos de 'convenientia'; término que Gracia ha traducido en inglés como 'agreeability' (Volveré a este punto). Por lo pronto, se puede notar la clasificación que Suárez hace de los tipos o rationes del bien. De tal suerte divide el bien entre el verdadero y el aparente, y acepta con modificaciones la distinción entre el bien en sí y el bien para otro. Pues aunque Suárez admite tales distinciones tradicionales, las re-significa; pues lo fundamental para él es que el bien en sí no difiere del ser en la realidad, ambos son términos coextensivos, solo difieren intensionalmente. La perfección es completitud de ser, es decir, la presencia en una cosa de todo lo que esa cosa debe tener, y todo lo que una cosa debe tener está determinado por su naturaleza. Por tanto la perfección de una cosa, es todo lo que tiene naturalmente, lo que es otro modo de referir a su ser.

En tanto, en la distinción conceptual entre el bien en sí y el bien para otro, introduce una importante nota común: que ambos bienes, el en sí y el para otro, incluyen la convenientia. Es decir, la capacidad, la inclinación, o la conexión natural ${ }^{31}$. Por lo tanto, el resultado de que el bien en sí y el bien para otro incluyan la conveniencia, los hace distinguirse intensionalmente del ser y la perfección. Porque ser sin más significa solo entidad y perfección, es decir, que a una cosa no le falta la característica, o las características que naturalmente debe tener. Pero la noción de bien,

28 J. Gracia, The Metaphysics of Good and..., 25-32.

29 SuÁreZ, DM, X I 19.

30 Tomás de Aquino, Summa Theologiae, I 5 a.1 (Marietti ed. Roma), vol. I, 29.

31 SuÁreZ, DM, X I 15. 
resignifica Suárez: "expresa un tipo de convenientia por la cual la cosa es deseable" 32 . De modo que, como afirma Gracia: "contrario a lo que Moore pensó, la bondad puede definirse, pero su definición no debe hacerse en términos de placer, virtud, deseabilidad o perfección"33.

De tal modo la bondad, según Suarez, consiste fundamentalmente en un tipo de conveniencia entre las cosas, lo que a su vez las hace deseables. En este importante asunto he preferido mantener el término conveniencia para traducir convenientia, en tanto Gracia lo traduce como agreeability. Por razones que Gracia mismo ofrece al decir que a 'convenientia' le corresponde morfológicamente la traducción de 'agreement' o 'acuerdo' en castellano. El contexto discursivo sugiere que Suárez está pensando en la característica de una cosa buena que la hace compatible, conveniente y comunicada satisfactoriamente con algo otro. La ventaja de usar acuerdo o agreeability es que tiene connotación ético-política, como también la expresión 'querer entrar en acuerdo', lo cual resulta apropiado al uso pragmático que abordaremos. En todo caso, para Suárez es importante distinguir entre las nociones de bondad y deseabilidad. 'Bondad' y 'deseabilidad' son términos coextensivos de la misma manera en que lo son 'ser' y 'bondad', pero como 'bondad' y 'ser' son términos intesionalmente distintos, también lo son los términos 'bondad' y 'deseabilidad'. Usa la metáfora "lo deseable se relaciona al bien como lo hace lo visible a lo iluminado" 34 . La deseabilidad, a diferencia de la conveniencia, refiere a una relación con la facultad de deseo y, por lo tanto, expresa algo formal, que 'el bien' como tal no expresa" ${ }^{35}$. Pero es por esta relación a lo deseable que la noción de bien tiene, además, carácter de fin, aunque de nuevo, es intensionalmente distinto de él ${ }^{36}$. En el mismo contexto, Suárez insiste que la conveniencia debe entenderse como una inclinación o capacidad de conexión y acuerdo (mientras que conveniens se entiende como algo valioso) no meramente como una compatibilidad, porque incluye no solo el hecho de que dos cosas puedan no interferir una con la otra, sino sobre todo que ellas estén dispuestas a estar juntas de cierta manera.

\footnotetext{
SuÁrEZ, DM, X I 18.

J. Gracia - D. Davis, The Metaphysics of Good and ..., 27.

SuÁrez, DM, X I 19.

SuÁrez, DM, X I 19.

SuÁreZ, DM, X I 21.
} 
Ahora bien ¡cómo puede derivarse de la ontología trascendental del bonum, bien ontológico o natural (así lo denominaron los escolásticos), una comprensión del bien moral en los hombres singulares y en los hombres en su conjunto? Un camino a seguir es el del análisis conceptual de las distinciones del bien, allí podremos determinar este vínculo. Suárez agrega otras cuatro divisiones conceptuales, estas son: (i) el bien que es conveniente por sí mismo y el bien que es conveniente por razón de otro; (ii) el bien noble, placentero o deleitable y útil; (iii) el bien natural y moral, y (iv) el bien sin cualificación y en cierto respecto. Primero, reconoce que entre estas distinciones conceptuales hay conexión y yuxtaposición de varias maneras. Aunque estos conceptos de bien difieren lógica o intensionalmente pueden hallarse o instanciarse en una misma cosa, porque la misma cosa puede, por ejemplo, ser noble, placentera y útil. El bien que es conveniente por sí mismo se divide, a su vez, entre bien noble (honestum) y placentero. En segundo lugar, y relevante a nuestro enfoque, Suárez considera que el concepto de bien noble (lo que posee valor), es un bien propio y conveniente por sí mismo, y constituye primariamente la noción de bien trascendental, porque "si el ser se dice [ser]-bueno en sí mismo, esa designación se toma de hecho de que tiene en sí mismo una perfección conveniente a sí mismo [...] Por tanto, la bondad noble de cierta manera es una propiedad universal del ser en el orden natural de donde el bien trascendental ha sido designado" 37 . De aquí se deriva que el bien sea deseable, porque es conveniente a la naturaleza. En el caso de los seres humanos en particular, los bienes nobles son aquellos que están en acuerdo con la recta razón, tal como la virtud $^{38}$ y con su naturaleza física, tal como la salud-prosperidad ${ }^{39}$. En tercer lugar, Suárez agrega otra distinción conceptual importante la cual incluye dentro del bien noble; es la del bien natural y moral; claramente enseña que esta última distinción no es pertinente a la metafísica, sino a la filosofía moral; cuestión que él mismo discute desde su óptica de teó$\log o^{40}$. Así, señala que el concepto de bien moral es el bien considerado

\footnotetext{
SuÁreZ, DM X I 10.

SuÁrEZ, DM X II 14.

SuÁrEZ, DM X II 15.

40 Cf. SuÁrez, DM X II 30-34. Indica que él ha abordado el bien moral en general como teólogo en su Comentario a la STh I-II q. 18; y en particular en su obra De fine hominis, donde expone ampliamente su doctrina del hombre como ser moral, y de Dios como su fin último o su felicidad.
} 
conveniente a una naturaleza racional. Y ya que la racionalidad es parte de la naturaleza humana, esto parece implicar que el bien moral es parte del bien natural, por consiguiente, en este punto la distinción natural/ moral desaparece ${ }^{41}$. Pero Suárez nota la dificultad explícitamente, por eso vemos que desde su metafísica ha planteado la interrogante sobre el orden práctico, cuestión que resuelve formulando la definición de bien moral en términos de: lo que es "adecuado a una cosa en tanto actúa libremente" ${ }^{42}$. Ambos conceptos de bien, natural y moral, tienen que ver con alguna actividad, pero en el caso del bien moral, tal actividad refiere a la actividad del ser libre. La libertad, por tanto, es condición necesaria de la bondad moral y aquello que demarca la distinción respecto del bien natural. Lo interesante para nuestro tema es lograr enlazar lo que aporta la teoría antropológico-jurídica a la noción de ser-en común o comunidad humana. Esa teoría antropológico-jurídica o de jurisprudencia según Suárez "no es más que una cierta aplicación o extensión de la filosofía moral. A la cual corresponde dirigir y gobernar las costumbres políticas de la república”³.

\section{Alcance del bien moral en SuÁrez}

El concepto (ratio) de bien por otro, como vimos, es coextensivo con el del bien moral, se instancia en la actividad libre de los hombres singulares en tanto surgen como miembros de una comunidad (la comunidad es un agrupamiento de hombres asociados bajo estado de derecho, en vista de un fin común y con alguna forma de jefatura), y así en la esfera

41 La mayor crítica a la posición del naturalismo ético desde los filósofos de la tradición empirista y analítica, particularmente desde D. Hume a G. E. Moore, se asocia a la falacia naturalista. Según Moore el término 'bien' es simple, no puede analizarse ni definirse, menos a partir de otras cualidades naturales y descriptivas. Tratar de definir el bien en términos de placer y de deseabilidad es incurrir en la falacia naturalista, porque se han confundido cualidades naturales sensibles con una cualidad evaluativa. El hecho que algo sea deseable, sea el perfume de una flor o el olor al tabaco, no son razones para derivar su bondad. El bien, añadirá Moore en Principia Ethica (1903), es algo de lo cual tenemos reconocimiento intuitivo.

42 SuÁreZ, DM X II 30.

43 M. Castro y otros (eds.) F. Suárez, De Legibus ac ..., 180. (En adelante F. Suárez, De Legibus ac). En el texto iuris civilis prudentia, tendría que traducirse literalmente por "prudencia -en el sentido de ciencia, conocimiento práctico- del derecho civil. N. de T. 
política del ser-en común. El lenguaje jurídico-político en el que tal concepto adquiere significado es el que hemos reunido en los conceptos de 'libertad', 'ley natural', 'poder político', 'salvación' y 'comunidad política perfecta', porque -como argumentamos- son conceptos que aparecen sustentados por principios del derecho y del bien común.

Acerca de la libertad: $\mathrm{O}$ del "estado de experiencia que se vive" -tema reconocidamente interdisciplinario de Suárez- es el vestigio que más asemeja el sujeto humano a Dios. De todos los poderes de la creación no hay otro comparable, de todos los agentes dotados de conocimiento no existe ningún otro dotado con tal poder para elegir amar, agradar, servir a Dios (lo dado, o bien absoluto) y alcanzar así la misma salud-prosperidad o salvación, como más adelante veremos. Suárez no está de acuerdo con las diversas definiciones escolásticas de libertad, no considera que sea lo mismo que la indiferencia del juicio, ni que el acto del apetito intelectual, ni de la potencia inmaterial y espiritual de poder o no hacer algo; ni un poder modificado por un hábito, y aunque admite con los demás escolásticos que en la indiferencia del juicio se halla la raíz de la libertad, corrige la semántica destacando que simplemente se trata de un poder (que posee la misma extensión que la 'voluntad') "tal que posee el mencionado poder y jurisdicción sobre su acto ${ }^{44}$ " o bien concebida desde la psicología que "es el dominio sobre los actos propios 45 ". Pero precisa: "es de esencia del poder libre, que por su intrínseca virtud y potestad pueda ejercer o suspender el acto" ${ }^{46}$. Concibe en este punto tal unión ontológica entre poder y acción que así articula la libertad del individuo para que funcione en el nivel pragmático y quede vinculada a la teoría jurídica y política; esfera donde, por una parte, manifiesta supremo dominio, y por otra, conveniencia con el imperio de la ley natural. En el De fine hominis, obra donde expone su doctrina del hombre como ser moral, y de Dios como su fin último, por una parte, insiste en que la acción libre de los seres humanos es condición de su fin: la felicidad ${ }^{47}$. Por otra

44 SUÁREZ, DM XIX 54.

45 SuÁrez, DA XII 2.

46 "Sine integra virtute activa nondum habet actum in manu sua" (DA XII 2). Consulto F. SuÁrez, Commentaria una cum Questionibus in Libros Aristotelis de Anima. Vol. I-III, C. Baciero y L. Baciero, Trads. (Editorial Labor, Madrid 1971-1991). En adelante, $D A$.

47 "La doctrina moral, es decir, los principios y fundamentos de todas las virtudes y acciones morales por las cuales ellas son conducidas a Dios." (SUÁREZ, 
parte, agrega que "la total naturaleza de la Providencia divina está en el gobierno y dirección de los seres humanos a su fin ${ }^{48}$ ". En verdad, para el teólogo Suárez, la extensión de la Providencia, el orden, las instituciones divinas y los medios por los cuales son dirigidos a su fin, incluye "a todas las criaturas de cierta manera"; esta "cierta manera" entiende que es la "humanidad [por la que] todos ellos logran su felicidad". Así pues, desde la doctrina teológica del Eximio y pío queda predefinido que todas las creaturas sean ordenadas a la salvación en tanto prosperidad de esa humanidad ${ }^{49}$. Mientras que la humanidad, políticamente definida "son los hombres reunidos por consentimiento común en un cuerpo político, a través del lazo de la amistad y para propósitos de ayudarse con un fin

De fine hominis, Prefacio). Su argumento de autoridad dice: "Algún último fin incondicional es dado para lo que (ad quem) y por lo que (propter quem) los seres humanos fueron hechos por el autor de la naturaleza. Esta conclusión, hablando estrictamente, es de fe. [...] y es evidente, en particular, que Dios es el fin último de los seres humanos que alcanzan a Dios, hablando estrictamente, de manera especial [...] lo cual abordaremos al tratar del objeto de la felicidad. Que un ser humano tiene un fin último comunicable a sí mismo es también conocido por la luz natural. (Suárez, De fine hominis, disp. 3, sect. 1; in Opera Omnia (ed. Vivès, Paris 1856-1877) vol. 4.)

48 Suárez, De fine hominis, Prefacio.

49 "Unde fit, ut omnia divina opera et mysteria, presertim supernaturalia, propter salutem humanam, maxime electorum, facta sint, atque ita considerando de homine, et de mediis, quibus ad finem suum perducitur, tota ratio divine providentice quodammodo exhauritur, quantum ab hominibus cognosci potest." (SUÁREZ, De fine hominis). Desde el punto de vista lógico-ontológico, "Suárez concibe el universal 'humanidad' identificable con la naturaleza del hombre, inmediatamente representable por las operaciones del intelecto. Según Suárez hay contradicción en postular la existencia de un hombre separado de la totalidad de los hombres singulares y que sea universal relativamente al mismo conjunto de hombres. Ser separado significa no estar intrinseca y esencialmente en ellos, lo que se opone a la comprensión del universal como lo que existe intrínseca y esencialmente en una totalidad de seres. Por una parte, la representación de la forma producida por el intelecto es inmediatamente universal, por otra la forma en-el-singular es siempre individualizada. Así la naturaleza humana desde el punto de vista de la unidad formal es efectivamente distribuida en la multiplicidad indefinida de los individuos, sin que sea puesta en cuestión la singularidad de su unidad. Y en cada individuo hay una universalidad potencial por el hecho mismo que la naturaleza humana expresa una comunidad entre ellos" (J. P. Coujou, "La constitution suarézienne de...", 601). (Mi traducción y cursivas) 
común" 50 , lo cual implica que "la humanidad es una unidad experimentada en concreto como sociedad universal" ${ }^{51}$.

Acerca de la ley natural: Desde el De legibus -donde construye su edificio jurídico-político-moral- Suárez insiste que los hombres alcanzan el camino de la salvación mediante sus actos libres y la rectitud moral la que, en gran parte como le importa subrayar aquí, depende de la ley considerada como regla de los actos humanos ${ }^{52}$. Queda claro que la ley es primariamente materia de una voluntad justa; que toda ley tiene raíz en la Ley Eterna, la cual es "decreto libre de la voluntad de Dios, estableciendo el orden que debe ser observado, ya sea generalmente por todas las partes del universo, o en relación al bien común o especialmente para ser observada por las criaturas dotadas de intelecto en sus operaciones libres" 53 . La ley, enfatiza Suárez, es necesaria para que la criatura racional viva de modo satisfactorio y conveniente de acuerdo a su naturaleza racional $^{54}$; los seres racionales pueden escoger, entre el bien y el mal, y por lo mismo son susceptibles de gobierno moral.

50 Suárez, DL, III, 2 4. Consulto L. Pereña y otros (Eds.), F. SuÁrez, De Legibus (Madrid: Editorial C.S.I.C 1971-1975). En adelante, DL.

51 M. Castro y otros (eds.) F. Suárez, De Legibus ac ..., 48.

52 Ya se había preguntado Suárez por la relación de la política con la moral, en términos de Utrum effectus a Lege intentus sit facere subditos bonos o si el efecto de la ley es subordinar a los súbditos al bien. Responde que: "las leyes civiles, que son estrictamente hablando leyes, actualmente no solo hacen el bien en un sentido calificado [de bien común], sino estrictamente hablando, porque ellas intentan el bien moral honesto. El Jurista declara esto respecto de la ley (1 ff. in De Iusticia et Iure), diciendo: 'Cultivamos la justicia”' (Suárez, DL I 13 6).

53 Cf. SuÁrez, DL, II 3 6. De la voluntad deriva toda la autoridad, de la voluntad de su autor, Dios Legislador. (Cf. M. CAstro, et al. F. Suárez, De Legibus ac..., 17). (Mi traducción) Suárez define que "Ley positiva humana es la ley hecha por los seres humanos, emanada directamente del poder y de la prudencia de ellos, e impuesta a los súbditos como regla y medida de sus obras" (SuÁrez, DL, I 3 17). Se subentiende que "el teólogo debe tratar todos los tipos de ley: la ley natural sujeta al orden sobrenatural y la ley humana o civil para determinar la respectiva rectitud a la luz de los principios y de las obligaciones en la conciencia" (SuÁrez, DL I Prologo).

54 Suárez acepta cuatro tipos de leyes: eterna, natural, divina y humana. En el legislador, divino y humano, y afirma que existen todos los tipos de ley, como acto de una voluntad justa que obliga al inferior a realizar un determinado acto, dirigido al bien común (SuÁrez, DL L I 12 6). 
En cuanto a la doctrina de la ley natural ${ }^{55}$, Suárez como Sto. Tomás admiten que deriva de la Ley eterna. Pero la ley natural no es decreto arbitrario de Dios: Es una ley que teniendo origen en Dios, precisa del concurso de la voluntad humana, puesto que Dios presupone el carácter moral de los actos humanos. Mientras que las leyes humanas civiles son concebidas para una comunidad política determinada; la ley natural comprende toda la humanidad. De modo que una vez reunida la comunidad de los hombres, opera la concesión divina de la ley natural. Procede entonces sistemáticamente vinculando los conceptos de razón, consciencia y ley ${ }^{56}$. De tal manera establece que la ley natural reside en la mente humana ${ }^{57}$. Lo cual permite que los seres humanos naturalmente disciernan lo que es moralmente bueno o malo. La ley natural es, además, preceptiva porque distingue el bien y el mal, comanda, prohíbe y permite; permite a los hombres libres reconocer cuáles son los actos compatibles con la naturaleza racional y cuáles incompatibles. Una vez que la ley natural distingue de suyo el bien y el mal, sin necesidad de referencia a Dios, la luz natural de la razón es suficiente para la promulgación de la ley natural ${ }^{58}$. De lo dicho hasta aquí, se ha hecho evidente que Suárez, en su calidad de teólogo moral, desarrolla una antropología teleológica, en el sentido que atribuye a todos los hombres una naturaleza ordenada a un fin último, trascendente y moral; todos los hombres

55 SuÁrez; DL L. II caps. 5-16.

56 Cf. G. Burlando, "Virtud política y método histórico rupturista en F. Suárez", Veritas 32 (2015) 65. Se discute que las virtudes políticas de justicia y equidad no solo regulan y miden las demás virtudes, sino a toda norma, incluyendo la ley. La ley no es ley, si no es justa. La justicia/equidad queda separada de la ley, se vuelve medida de esa. Hay, por tanto, preeminencia de la razón y, por así decir, una Super virtud sobre la ley. Todo lo cual le confiere al individuo derecho de juzgar la justicia de la ley.

57 Lex ergo naturalis propria, quae ad moralem doctrinam et theologia pertinet, est illa, quae humanae menti insidet ad discernendum honestum a turpi. (SuÁrez, DL I 3 9) La ley natural es la ley que reside en la mente humana para discernir lo honesto respecto de lo torpe. Sobre esta definición se llama "la atención sobre el inciso referente a que se trata de la ley que pertenece a la doctrina o filosofía moral y a la teología moral como dando a entender que no es dominio por el que deba aventurarse a teorizar el jurisprudente meramente juristécnico o jurisconsulto, sino solo el jurisprudente filósofo o moralista, en cuanto no deja de ser contradictorio con el núcleo de la definición" (F. Puy, "Los conceptos de derecho, justicia y ley en el De legibus de Francisco Suárez (1548-1617)”, en Persona y Derecho, 40 (1999) 175-195).

58 SuÁrez, DL L II 624. 
son iguales, por ser dotados de razón, y todos son libres por naturaleza al no estar sometidos a otros semejantes. Pero ¿̇entonces cómo se justifica la obligación de la obediencia a las leyes y el poder político?

Acerca del poder político y sentido teológico-político de la salvación: En el libro III del De legibus - donde trata del derecho positivo- Suárez formula una pregunta y responde radicalmente como algunos antecesores suyos ${ }^{59}$. Su planteamiento es si acaso: “¿Existe un poder humano para obligar a otros hombres mediante la ley?"60, a lo que responde: "hay que atender a que la naturaleza humana es libre" ${ }^{1}$. Sin embargo, aquí advierte: "la libertad individual es compatible con la sujeción, porque según la ley natural existen cosas ordenadas, prohibidas y cosas permitidas." La respuesta de Suárez reconoce un conflicto entre autonomía y autoridad, entre libertad y poder político. ¿Cómo entonces, si es que de alguna manera, puede justificarse el poder político? Ante este dilema, los filósofos políticos proponen una variedad de respuestas. Algunos han sostenido que se justifica por las buenas consecuencias, otros niegan que haya alguna justificación para el poder político y otros, entre ellos Suárez, defienden que este poder se basa en un cierto tipo de acuerdo. Pero, como Suárez suscribe derechos naturales substanciales a los individuos, necesita hallar razones morales para justificar la obligación: el deber político de todos los individuos a su gobierno ${ }^{62}$. Esas razones morales ya

59 E. DE LA BoÉTIE (1530-1563), Discours de la Servitude volontaire. (c. 1548); y J. DE MARIANA (1536-1624), De rege et regis institutione, liv. I cap. I. (Toledo, 1599). [Del rey y de la institutición real (BAE, Madrid 1950, vol. 31)].

60 "[...] Itaque quaestio est an homines, ex sola rei natura loquendo, possint imperare hominibus per propias leges eos obligando" (SuÁreZ, DL III 1 1).

61 "[...] quia homo natura sua liber est" (SuÁREz, DL III 1, 1). Suárez ofreció una multidimensional síntesis sobre la libertad humana. Su enfoque metafísico de la libertad aparece en su obra señera, Las Disputaciones Metafísicas, disp. XIX, sec. 2-9 Mientras que su enfoque teológico, en el De Gratia, donde nos hace notar como fenomenólogo, que la libertad es un estado de experiencia interior que se vive, y no un objeto. (SuÁrez, De Gratia, prologo I cap. 4 15) Para un enfoque moral de la libertad en Suárez, véase G. Pistacchini, A Modernidade Filosófica de..., 243 ss.

62 Antes que Locke, como hemos establecido en otro estudio, Suárez aborda el problema de la obligación política defendiendo uno de los dogmas más fuertes de la tradición democrático-liberal, i.e., que un gobierno legítimo es imposible sin el consentimiento del gobernado. Efectivamente, la teoría contractualista de Suárez defiende las bases morales para resignificar la relación del individuo y el Estado liberal moderno de su época. En ese sentido hemos destacado los rasgos fundamentales del incipiente Estado liberal (Cf. G. Burlando, "Defensas históricas del 
se habían articulado en el Prólogo al De legibus. Allí se discurre teológicamente, asumiendo que la finalidad de la teología es el ser humano, su salvación y que la teología católica es esencialmente soteriológica, es decir, su objetivo primordial no es teórico, como sería el afán especulativo de sabiduría, sino pragmático, en tanto que se propone conducir a las almas a la vida eterna, a Dios y su fin último ${ }^{63}$.

El enfoque de Suárez en su tratado De legibus es el de un teólogo moral y, en este sentido, aborda la autonomía y dignidad del ser humano que vive según las leyes de la libertad, estableciendo el orden moral como lugar propio de la criatura racional a partir de que esencialmente participa del principio absoluto de la moralidad ${ }^{64}$. Como observa Pistacchini: "Dios debe ser considerado por el teólogo, más allá de muchos otros aspectos, también en aquel en que es el fin último, para el cual tienden las criaturas que participan de razón y en lo cual consiste su única felicidad" "65. Además, importa notar que Dios se relaciona amorosamente a los hombres interviniendo en la historia: "Dios, en verdad, no es solamente el fin, y por así decir, la meta a la cual tienden las criaturas intelectuales, sino también quien establece el camino para alcanzarlo"66.

Otra premisa teológica de nuestro autor es que Dios respeta siempre la naturaleza de sus criaturas, en este sentido la concurrencia con las criaturas racionales es esencialmente moral. El camino por la cual Dios conduce a los hombres es de índole moral, ya que "ilumina con ense-

poder político: F. Suárez y J. Locke teóricos de la moralidad por el acuerdo”, en R. Pich, A. Culleton (eds.), Right and Nature in the First and Second Scholasticism, vol. «Rencontres de philosophie médiévale» (Turnhout Brepols, Belgique 2014) 339).

63 La causa formal de la teología es la dimensión de la gracia divina, pues, "la revelación y la fe teologal son gracias; asimismo la redención es una gracia y la fuente de todas las gracias con las que Dios socorre al hombre. Así que toda la revelación se ordena a la redención, como esta a la salvación del hombre. A su vez, la obra de la salvación resulta del mérito sobrenatural al que la gracia eleva los actos humanos. En suma, la bienaventuranza eterna, a la que el hombre está llamado después del sacrificio redentor de Cristo en la cruz, y por virtud de Él, es la causa formal y final de toda la ciencia teológica, la cual, consumada, es lo mismo que el Dios redentor y santificador pretende" (C. R Kuri, "Francisco Suárez, teólogo y filósofo de la imaginación y la libertad", en Revista de Filosofía, 58 (2008) 88).

64 G. Pistaccchini, A Modernidade Filosófica de..,, 231. (Mi traducción del Portugués)

65 Suárez, $D L$, Prólogo, p. IX.

66 Suárez, DL, Prólogo, IX. 
ñanzas, los advierte con consejos y los obliga con leyes, y sobre todo los ayuda con los auxilios de su gracia, por lo que justamente Isaías puede proclamar El Señor es nuestro legislador, el Señor es nuestro rey, Él nos salvará" (Cf. Is 33, 22). El énfasis de Suárez es que el camino de salvación de los hombres radica en sus acciones libres: en la rectitud de sus costumbres. Y "porque la rectitud de las costumbres depende en gran medida de la ley como regla de las acciones humanas, la consideración de la ley cabe naturalmente y en gran parte a la teología: que en cuanto sagrada doctrina discute acerca de las leyes, en verdad no hace otra cosa que contemplar al mismo Dios en cuanto legislador" ${ }^{37}$. Por consiguiente, es en el orden moral que la libertad humana se realiza y, realizándose, se descubre ordenada y vinculada a Dios en cuanto legislador ${ }^{68}$. Lo moral, según Suárez, queda establecido como lugar propio de los hombres y su alcance llega hasta la ley. Por eso se había formulado que la ley es la medida, no de cualquier acto, sino de los actos morales, en cuanto a su bondad y rectitud; en razón de lo cual esta induce a tales actos imponiendo claramente una necesidad moral de operar, esto es, un vínculo de consciencia u obligación ${ }^{69}$.

Acerca del sentido fuerte de comunidad política en Suárez como sociedad perfecta: La doctrina política de Suárez ha supuesto que el hombre es persona singular, aunque constitutivamente no clausurada en sí misma, ni distanciada de la humanidad, sino en conexión y comunicación con lo otro. Por lo mismo, puede considerarse a este hombre en cuanto animal social y entenderse que tiene el deseo natural de vivir en comunidad $^{70}$. La familia es la más fundamental de las comunidades sociedales pero, siendo útil para los efectos del gobierno doméstico y la economía, es imperfecta para la plena realización humana. Con el fin de preservar la paz entre todos e implementar la civilización, las familias se asocian formando una comunidad civil o política, que Suárez propone como comunidad perfecta. Así pues, tal como el cuerpo humano tiene que poseer una potencia anímica que lo conduzca a su bien propio, en

SuÁrez, DL, Prólogo, IX.

68 Cf. G. Pistacchini, A Modernidade Filosófica de..., 232.

69 Suárez, DL I, 1, 1, p. 2-3, en cita de Pistacchini, A Modernidade Filosófica de..., 233.

70 SuÁrez, DL III, $1,3$. 
cada comunidad perfecta debe existir un poder gobernante que oriente hacia el bien común de la comunidad ${ }^{71}$.

Se puede notar que en Suárez la comunidad política no es obra y resultado de la corrupción como pensaron algunos Padres de la Iglesia ${ }^{72}$, no sería el resultado de una unidad artificial física y orgánica, donde la razón universal es sustituida por una razón terrenal y laica del sobera$\mathrm{no}^{73}$. Tampoco sería consecuencia de una condición imaginaria como la del "estado de naturaleza" postulada por Locke, condición en la que los individuos carecen de organización política, pero pueden elegir y acordar formar un Estado político; si lo hacen estarán motivados por sus intereses individualistas para lograr protección a sus derechos tales como: la vida, la libertad, la propiedad y todas las ventajas que ofrece un Estado político que permitiría escapar a los inconvenientes propios del estado de naturaleza ${ }^{74}$. La comunidad de Suárez es muy diferente incluso del "Mitsein mit Anderen" pensado fenomenológicamente por Heidegger. Sea esta expresión traducida como ser-con o como coestar con los otros, en la que su significado apunta al 'con' o al 'co-' de 'comunidad'. La descripción suarista de comunidad perfecta no implica un 'con' o 'co-seco, neutro y separado de otros, en el que el individuo está proyectado en el mundo compartiendo apenas un lugar, a lo sumo un contacto: un mero estar- junto o, si se quiere, un estar-en-medio-de, frente, sin proximidad a los otros y, claramente, sin ensamblaje.

En Suárez la vida en comunidad es consecuencia de la naturaleza no unidimensionalmente ontológica, sino también política del ser humano. Piensa efetivamente que:

71 SuÁREZ, DL III 14 . El poder legislativo caracteriza la magistratura con suprema jurisdicción, o soberanía política.

72 Cf. M. Castro y otros (eds.) Suárez, De legibus ac..., 29.

73 Cf. T. Hobbes, Leviathan, Or the Matter, Form and Power of a Commonwealth Eccesiasticall and Civil, M. Oakeshott Ed. Con Introducción de Richard S. Peters (Collier Books Macmillan, New York 1962).

74 La función del Estado de Locke es implementar y asegurar los derechos que deben tener los individuos. Ellos no entrarian a la sociedad política a menos que sus derechos estuvieran protegidos. Así que para justificar su existencia y las inconveniencias que impone en los hombres, el Estado debe hacer una mejor labor de protección de los derechos de la que harían los individuos por sí mismos. (Cf. Locke, Two Treatises..., cap. II 4-15, 309-318). 
La comunidad política es perfecta por definición. La comunidad política es perfecta porque ella basta para alcanzar la felicidad humana en el plano temporal, y por ser perfecta no forma parte de otra comunidad superior del mismo orden. Ahora bien, el signo por excelencia del carácter de perfecta de esa sociedad reside en el hecho de que su autoridad posee la nota específica de suprema. En efecto, la potestas jurisdictionis, que es la propia de la sociedad política, es superiorem non recognoscens (in suo ordine-temporali) $)^{75}$. (Agrego cursivas)

El énfasis original de Suárez está en el tipo de ensamblaje entre el carácter, de estado del derecho, y el fin de la comunidad, un fin común y con alguna forma de jefatura, la cual tiende no a la felicidad futura de sus miembros, ni tampoco a la felicidad presente en toda su extensión posible, sino a la felicidad natural que deriva de la condición constitutiva de ser una sociedad perfecta, cuya propiedad de segundo orden es ser suprema $^{76}$. Esto quiere decir que no se sujeta a otra comunidad política de su misma esfera temporal -ella es su instancia última de conducción, legislación y jurisdicción- y se identificará con la potestad de régimen de la comunidad, que es política en sentido estricto, i.e., de la comunidad políticamente autárquica o autosuficiente en el orden temporal ${ }^{77}$. A la vez los individuos singulares, en tanto están ensamblados en esa comunidad por ley natural (ya que una vez reunida la comunidad de los hombres, opera la concesión divina de la ley natural), comparten en ella propósitos, obligaciones, responsabilidades y fines comunes. Políticamente hablando, los individuos singulares de Suárez son todos iguales ante la ley. Dicho de otro modo, desde la perspectiva ontoteológica, los reúne un fin último trascendente; no obstante, eligen libremente no solo los medios, sino el fin último mismo, ya que pueden elegir amar a Dios o lo contrario ${ }^{78}$. Los hombres pueden elegir también sus fines

75 S. R. Castaño, "Potestad Suprema e independencia como notas de la república en Vitoria y Suárez", en M. Caciolini (ed.), Gli strumenti del potere. Dal principe all'archeologo, Lo Sguardo, Rivista di Filosofia 13 (2013) 80.

76 SuÁrez, DL I, VI, 22.

77 "Tal es el "signo" de la communitas perfecta, decía Suárez en lograda expresión. Signo que se constata cuando en tal principado o república hay un tribunal en el que terminan todas las causas de ese principado, y no es posible apelar a otro tribunal superior. Pues cuando hay lugar a apelación se da el signo de principado imperfecto, ya que la apelación es un acto del inferior al superior." (S. R. CASTAÑo, "Potestad Suprema e independencia ...", 83).

78 Cf. SuÁrez, DA XII, 2. 3. 
temporales, pues son individuos que construyen su dignidad y su plena realización a partir del orden comunitario/social. De ahí que, como nota Cedroni, en Suárez el cuerpo político es comunidad perfecta, donde los ciudadanos actúan en una esfera autónoma -sin sustraer espacio al soberano- y encuentran su dimensión original y auténtica propiamente en la convivencia política. La communitas perfecta de orden temporal ideada por Suárez "es democracia originaria fundamental, precedente, lógica y ontológicamente, cualquiera sea la forma de régimen político"79. A través del pacto constitucional estipula el pueblo las condiciones y limitaciones del Rey en el ejercicio del poder político. Formal y materialmente la institución monárquica se justifica en cuanto es un instrumento al servicio del bien común y viene legitimada por la voluntad popular. En función del dinamismo del bien común prevé Suárez la posibilidad de un auténtico control democrático ${ }^{80}$.

Si todos los hombres son por naturaleza libres y no sujetos a ningun otro, el gobierno [y en particular las leyes a las cuales se someten todos por igual] se justifica solo en cuanto necesario para la promoción y conservación del bien común ${ }^{81}$. El proceso de tránsito desde la libertad a la obediencia debida se realiza solo por el método del acuerdo. A diferencia de Hobbes y Locke, en Suárez los individuos no son psicológicamente temerosos y egoístas como átomos cerrados, motivados solo por el interes individual, sino singular y naturalmente capaces de comunicarse con otros, en una comunidad de fines acordados. A diferencia de Heidegger, en Suárez no hay dualismo radical entre individuo y comunidad, en la que el dasein es el único auténticamente trascendente ${ }^{82}$, el que se responsabiliza por llevar a cabo toda la tarea de un eigentliches Sein (o Ser auténtico), mientras que la comunidad humana es únicamente un re-

\section{Cedroni, La comunità perfetta..., 80. \\ 80 SuÁrez, $D L$, Prólogo, LXVIII.}

81 Los filósofos cristianos en general se ha preocupado de abordar la cuestión de la relación entre el bien común y el bien individual; y de la relación entre bien común y el bien temporal, en cuanto a esta última, coinciden en defender el carácter temporal del bien común por estar basado en la condición natural, es decir, temporal, del hombre. El bien común no puede proveerle más que los medios necesarios para el bienestar y la felicidad en este mundo; hay cierto consenso en que es el Estado, donde radica dicho bien común. (Cf. S. Magnavacca, Léxico técnico de filosofía medieval, (Miño y Dávila, Buenos Aires 2005 116).

82 M. Heidegger, Los problemas fundamentales de la fenomenología (Trotta, Madrid $2000357)$. 
ceptáculo para ese dasein caído y pasajero. En Suárez la comunidad juega un papel significativo de convivencia política, en la formación moral de los individuos quienes están relacionados tanto con los otros semejantes, como con la fuente suprema que trasciende su $\operatorname{ser}^{83}$.

La comunidad suarista no tiene un carácter débil, instrumental, ni impersonal ${ }^{84}$, ya que sus individuos no se unen a ella para sacar ventajas particulares, sino buscando su desarrollo y felicidad integral. Los fines de la comunidad como tal tienen vínculos morales que garantizarán al individuo singular las condiciones de su buen vivir ${ }^{85}$ en toda su complejidad. Esta comunidad que se organiza y opera políticamente se puede denominar fuerte en tanto que funciona autárquicamente frente a otras comunidades. Conviene tener presente que, lo que hace a su sistema de gobierno moral y jurídicamente legítimo es: tanto la congruencia de los decretos civiles con las leyes de la naturaleza, como el acuerdo contractual comunitario entre sus miembros. En este aspecto se muestra el genuino estilo teológico - jurídico de nuestro autor.

\section{A MODO DE CONCLUSIONES}

Desde la discusión contemporánea de estos temas es posible cuestionar a Suárez por su ethos de índole teológico, que implica vínculos índisolubles entre los ámbitos de la naturaleza y la experiencia moral; por aceptar además que en la humanidad haya fines determinados, sin los

83 Para una crítica de Edith Stein al concepto heideggeriano de Mitsein cf. G. BurLANDO, "Un análisis interno del Dasein ontológico de Heidegger: críticas externas de Edith Stein”, B. Silva Santos (ed.), Mirabilia Arte, Critica e Mistica, 20 (2015) 365-382.

84 Para una discusión sobre los sentidos de comunidad débil y fuerte en el contexto de las teorías contemporáneas de justicia véase B. L. Pickett, "Sandel, Ontology, and Advocacy", Political Science Reviewer, 27 (1998) 334-359.

85 El buen vivir, la felicidad, o el sumak kawsay de los otros, como se entiende incluso en el mundo andino amazónico de Latinoamérica. Se reconoce oriundo de ontologías relacionales que alcanzan su máxima expresión en el establecimiento de la Constitución ecuatoriana, el derecho "de la población a vivir en un ambiente sano y ecológicamente equilibrado, que garantice la sostenibilidad y el buen vivir, Sumak Kawsay", en la que se explicita además que esa es la finalidad última del desarrollo." (V. Bretón, D. Cortez, F. García, "En busca del sumak kawsay", Ikonos, 48 (2014) 9-24). 
cuales no se entiende la tradición moral; por postular una ley natural establecida por el ser divino; por admitir universales tanto de las cosas naturales como artificiales, y tomar estos paradigmas para derivar resultados prácticos. Sin embargo, no me parece apropiado criticarlo fuera de su contexto histórico, por su alerta a los signos de su tiempo, o por haber elaborado una metafísica trascendental que contiene ramificaciones valóricas, y que marcará sus huellas profundas en el pensamiento moderno y contemporáneo.

En resumen, he sugerido que: (i) el término 'trascendental' en las Disputaciones Metafísicas denota tanto la abstracción misma como su término singular: el objeto. Desde este punto de vista, se ha implicado el mencionado giro hacia el mentalismo como una excursión al ámbito de los supertrascendentales ${ }^{86}$. Este giro resultó extraordinariamente relevante para establecer que el centro metafísico de Suárez aparece como ciencia de las razones universales trascendentales. En este trabajo se ha insistido en la perspectiva de que: "La metafísica consiste en un análisis del ser y de la comprensión de las determinaciones trascendentales, que están vinculadas al punto de convertirse en el mismo ser, ya que, por una parte, la comprensión de la filosofía especulativa queda articulada en Suárez en la constitución de una ontología trascendental, y por lo mismo, ella no deja de plantear en sus desarrollos las interrogantes del orden práctico, propio al despliegue de la razón metafísica" ${ }^{87}$.

En suma, lo que estuvo en juego en esta discusión, corresponde precisamente a una renovación del pensamiento sobre el individuo y del ser-en-común, destinado a complementar la articulación del ser. (ii) Hemos visto también que la noción del trascendental bonum de Suárez, permitiría el discurso sobre la idea de bien en general, y su correspondiente transposición a la idea del bien moral en particular, el cual quedó redefinido en relación a lo otro; ya sea: como capacidad de conexión natural, de conveniencia, o capacidad de acordar con otros. Entretanto esta temática se instala con el lenguaje pragmático de la libertad, la ley natural, el poder político, la salvación teológico-política, y la comunidad perfecta, sustentada en los principios del derecho y del bien común. (iii) Por último, aludimos a que el gobierno político de Suárez, tiene como

86 J. Doyle, "Hispanic Scholastic Phylosophy", The Cambridge Companion to Renaissance Philosophy, Cambridge U. P., Cambridge 2007 250-269).

87 J. P. Coujou, “La constitution suarézienne de...", 601. 
condición sine qua non el método del acuerdo voluntario, sin coerciones, como condición que le confiere su legitimidad moral. Interesó también contrastar algunas diferencias con los métodos contractualistas de Locke y Hobbes, en los que la promesa contractual no aparece vínculada a un bien trascendental. Notamos en este punto que el acuerdo voluntario de Suárez conlleva la obligación política, establecida por un vínculo moral trascendental. Adicionalmente, una contraposición a la descripción postmoderna del Mitsein de Heidegger, demuestra que fue Suárez y no Heidegger, quien se atrevió a extraer implicaciones pragmáticas de su metafísica trascendental, para así postular un individuo singular no distanciado, sino conviviendo en una comunidad auténtica y perfecta.

Dicho de otro modo, el punto de inflexión en la mirada holística de Suárez, se caracteriza por estar legitimada por un especial acuerdo: entre los decretos del gobierno civil de la comunidad temporal, con las leyes naturales intemporales. Parece muy claro para estudiosos, como Castro Henriques, Maltez, Morão, y Pistacchini Moita, que el legado más importante en la reflexión política de Suárez para la discusión contemporánea es su visión de que la vida en comunidad depende del primado de las leyes ${ }^{88}$. En esto Suárez, coincidirá con Bodin en que el atributo supremo de la soberanía es el poder de dar 'leyes' a los ciudadanos. Pero a diferencia de Bodin, sostiene que la soberanía, entendida en este sentido, no es propiedad absoluta del soberano, sino de la comunidad política. Finalmente, esta visión refleja el carácter que Suárez atribuyó al individuo singular. A diferencia de concebir un sistema de democracia liberal de laisse faire, o como una cierta "sociedad anónima cuyos miembros han firmado la asociación para el beneficio propio y han conservado el control último de la empresa ${ }^{89}$, Suárez modeló una relación entre el individuo y el Estado en un sistema comunitario, políticamente fuerte y público, de justicia distributiva y legal, que convierte el bien común en deber específico de la colectividad y de cada uno de los ciudadanos, en particular del superior. Por lo tanto, de tales condiciones, de equidad de deberes y fines acordados, resultaría un mayor bienestar social, lo cual equivale a caminar con pie seguro hacia el cumplimiento, prosperidad y salvación de la humanidad. Esta soteriología comprende no solo el

88 M. Castro y otros (eds.) F. Suárez, De Legibus ac ..., 48, 136.

89 W. T. Jones, A History of Western Philosophy, (California Institute of Thechnology Harcourt Brace Jovanovich Publishers, San Diego, New York, Chicago 1969) 278. 
aspecto sobrenatural eterno, alcanzado con el auxilio de la gracia divina, sino su salvación concreta, en el buen vivir terrenal de los hombres singulares, con el auxilio de su activa participación social y política ${ }^{90}$.

90 Perspectiva que permite revisitar a Suárez hoy en día como pionero en casuística. Schloesser destaca que Stephen Toulmin ha escrito: "In practical disciplines, questions of rational adequacy are timely not timeless, concrete not abstract, local not general, particular not universal. They are the concern of people whose work is centered in practical and pastoral activities"; una característica distintiva, según dice, que trazaron los jesuitas humanistas del Renacimiento. (Cf. S. Schloesser, S.J. Book Reviews: Lukás Novák, ed. Suárez's Metaphysics in Its Historical and Systematic Context. Contemporary Scholasticism vol. 2. Berlin; Boston: De Gruyter, 2014. Victor M. Salas and Robert L. Fastiggi, eds. A Companion to Francisco Suárez. Brill's Companions to the Christian Tradition vol. 53. Leiden; Boston: Brill, 2015. Journal of Jesuit Studies, (2016) 99). 
